\title{
Effect of Compositional Dependence on the Physical Properties of Sn-Se-Sb Chalcogenide Glasses
}

\author{
Lalit Kumar Abhilashi ${ }^{1}$, Pankaj Sharma ${ }^{2, *}$, Rahul Vaish ${ }^{3}$, Parikshit Sharma ${ }^{4}$ \\ ${ }^{1}$ Department of Electronics, Sai Nath University, Ranchi, India \\ ${ }^{2}$ Department of Physics and Materials Science, Jaypee University of Information Technology, Waknaghat, Solan, India \\ ${ }^{3}$ School of Engineering, Indian Institute of Technology, Mandi, India \\ ${ }^{4}$ Department of Physics, Abhilashi University, Mandi, India \\ *Corresponding Author: pks_phy@yahoo.co.in
}

Copyright $(2015$ Horizon Research Publishing All rights reserved.

\begin{abstract}
Sn}_{13} \mathrm{Se}_{87-\mathrm{x}} \mathrm{Sb}_{\mathrm{x}}(\mathrm{x}=0,3,6,9,12)$ glassy system is synthesized by melt quench technique. This glassy system has been studied for various physical parameters viz. coordination number, lone pair of electrons, number of constraints, bond energy, heat of atomization, glass transition temperature, cohesive energy, band gap and mean bond energy. From the physical analysis it is generalized that the average number of constraints, average heat of atomization, mean bond energy, glass transition temperature and cohesive energy are found to increase whereas numbers of lone pair of electrons calculated are found to decrease with the increase in the antimony content in the composition of the alloy. The increase in glass transition temperature has been explicated on the basis of accumulation of antimony atoms in selenium chain.
\end{abstract}

Keywords Sn-Se-Sb, Glass, Mean Bond Energy, Cohesive Energy, Melt Quench

\section{Introduction}

In the present electronic era chalcogenide glasses have attracted the attention of various researchers due to their potential applications in active as well as passive solid state electronics and optical devices. Chalcogenide glassy system based expertise is utilized in various fields like thermal imaging, switching memory, integrated fiber optics, photo detectors, photoreceptors, photovoltaic cells, ultra high density phase change storage and memory, optical fibers, photoresist [1-9]. Modern chalcogenide glasses are extensively used in rewritable optical disks and phase change memory devices. Since they are fragile glass formers, therefore by applying heat they can be switched between an amorphous and a crystalline state. This transformation helps these glassy systems for the storage of information by changing their optical and electrical properties [10]. Many chalcogenide glasses exhibit several non linear optical effects such as photo induced refraction and electron induced permittivity modification $[11,12]$. Chalcogens with their two fold coordination and lone pair orbits offer the network the dual channels of structural and electronic flexibility for removal of dangling bonds. As a consequence a typical chalcogenide has a relatively sharp optical absorption edge, single electrical activation energy and efficient photo excited conductivity and luminescence. All these properties are characteristic of a well-defined and clean forbidden gap. Thus due to the impurity effects of amorphous chalcogenide glasses they have immense importance in electrical, optical and magnetic properties $[13,14]$. These impurity effects are strongly related to the composition of the glass, chemical nature of the impurity and method of doping. Thus the impurity concentration is one of the major factors which allow improving various physical properties of amorphous materials by addition of certain impurities. Selenium based amorphous glasses are highly hailed due to their high viscosity. The addition of impurities allows the selenium based alloys to attain more sensitivity, greater hardness, small ageing effect and higher crystallization temperature. The addition of $\mathrm{Sb}$ in the $\mathrm{Sn}-\mathrm{Se}$ system may change its optical and electricalproperties significantly. This stimulated us to study the $\mathrm{Sn}-\mathrm{Se}-\mathrm{Sb}$ system which varies from floppy mode to rigidmode. The Se- Sn system is of special interest in view of the fact that it forms glasses over a wide domain of composition [15]. Addition of third element like Sb, As, Te, In etc. increases the glass forming region as well as it creates the compositional and configurational disorder in the system. Each impurity may satisfy its valence requirements by adjusting with its nearest neighbor's environment. This fact leads to a belief that properties of amorphous semiconductors are weakly affected by the addition of impurities but recently it has been reported that the addition of metal impurities may increases the refractive index and lowers the optical band gap significantly [16]. Thus the addition of $\mathrm{Sb}$ to the $\mathrm{Sn}$-Se system may be likely to change its optical and electric properties significantly. This brace us to study the $\mathrm{Sn}_{13} \mathrm{Se}_{87-\mathrm{x}} \mathrm{Sb}_{\mathrm{x}}(\mathrm{x}=0,3,6,9,12)$ glassy system 
which varies from floppy mode to the rigid mode.

The present paper deals with the compositional study of $\mathrm{Sn}_{13} \mathrm{Se}_{87-\mathrm{x}} \mathrm{Sb}_{\mathrm{x}}(\mathrm{x}=0,3,6,9,12)$ glassy system for various physical parameters. The physical parameters viz. coordination number, number of constraints, number of lone pair electrons, bond energies of the different bonds formed in the system, heat of atomization, cohesive energy, mean bond energy, glass transition temperature are theoretically studied for the $\mathrm{Sn}-\mathrm{Se}-\mathrm{Sb}$ glassy system.

\section{Experimental}

Glassy alloys of $\mathrm{Sn}_{13} \mathrm{Se}_{87-\mathrm{x}} \mathrm{Sb}_{\mathrm{x}}(\mathrm{x}=0,3,6,9,12)$ system were prepared by melt quench technique. The different compositional materials $(99.999 \%$ purity) were weighed according to their atomic percentages and sealed in evacuated (at $\sim 10^{-4} \mathrm{~Pa}$ ) quartz ampoules. The sealed ampoules were then kept inside a furnace where the temperature was increased up to $800^{\circ} \mathrm{C}$ at a heating rate of $3-4^{\circ} \mathrm{C} / \mathrm{min}$. The ampoules were then frequently rocked for 8 $\mathrm{h}$ at the highest temperature to make the melt homogeneous. The quenching was done in the ice cold water. Thin films of glassy alloys were prepared on glass substrates by vacuum evaporation technique at the room temperature and with the base pressure of $10^{-4} \mathrm{~Pa}$. The glassy substrates were firstly cleaned by soap solution at room temperature using ultrasonic cleaner then with double distilled water, a dip in acetone followed by ethyl alcohol, dried in an oven at approximately $110^{\circ} \mathrm{C}$. The bulk as well as thin films of the samples prepared were characterized by X-ray diffraction technique and found to be amorphous in nature as no prominent peak was observed in the spectra.

\section{Results and Discussions}

\subsection{Calculation of coordination number $(m)$ and number of constraints in glassy network}

The coordination number of glasses varies with their varying compositions, so it is of immense importance to calculate the average coordination number $<\mathrm{m}>$. The average coordination number in $\mathrm{Sn}_{13} \mathrm{Se}_{87-\mathrm{x}} \mathrm{Sb}_{\mathrm{x}}(\mathrm{x}=0,3,6,9$, 12) glassy system has been calculated by using the standard relation:

$$
m=\frac{\alpha N_{S n}+\beta N_{S e}+\gamma N_{S b}}{100}
$$

where $\alpha, \beta$ and $\gamma$ are the atomic \% of $\mathrm{Sn}, \mathrm{Se}$ and $\mathrm{Sb}$ respectively and $\mathrm{N}_{\mathrm{Sb}}, \mathrm{N}_{\mathrm{Se}}$ and $\mathrm{N}_{\mathrm{Sb}}$ are their respective coordination numbers. Average coordination number $<\mathrm{m}>$ is an important contrivance for the ternary system $\mathrm{Sn}_{13} \mathrm{Se}_{87-\mathrm{x}} \mathrm{Sb}_{\mathrm{x}}$ $(\mathrm{x}=0,3,6,9,12)$ to test the validity of topological concepts $[17,18]$ because of its large glass forming domain. The calculated coordination numbers $<\mathrm{m}>$ lie in the range $2.26 \leq$ $\mathrm{m} \leq 2.38$ and are given in Table 1 . The calculated values of the coordination number in $\mathrm{Sn} 13 \mathrm{Se} 87_{-\mathrm{x}} \mathrm{Sb}_{\mathrm{x}}(\mathrm{x}=0,3,6,9,12)$ glassy system increases with increase in $\mathrm{Sb}$ content. This fact attributes to the fact that the alloys are compactly packed.

Table 1. Describes the values of the average coordination number $<\mathrm{m}>$, number of constraints arising from bond stretching $\left(\mathrm{N}_{\mathrm{a}}\right)$, number of constraints arising from bond bending $\left(\mathrm{N}_{\mathrm{b}}\right)$, average number of constraints $\left(\mathrm{N}_{\mathrm{c}}\right)$ and effective coordination number $<\mathrm{m}_{\mathrm{eff}}>$ for $\mathrm{Sn}_{13} \mathrm{Se}_{87-\mathrm{x}} \mathrm{Sb}_{\mathrm{x}}(\mathrm{x}=0,3,6$, 9,12 ) glassy system.

\begin{tabular}{|c|c|c|c|c|c|}
\hline Composition & $\mathrm{m}$ & $\mathrm{N}_{\mathrm{a}}$ & $\mathrm{N}_{\mathrm{b}}$ & $\mathrm{N}_{\mathrm{c}}$ & $<\mathrm{m}_{\text {eff }}>$ \\
\hline $\mathrm{Sn}_{13} \mathrm{Se}_{87}$ & 2.26 & 1.130 & 1.52 & 2.650 & 2.26 \\
\hline $\mathrm{Sn}_{13} \mathrm{Se}_{84} \mathrm{Sb}_{3}$ & 2.29 & 1.145 & 1.58 & 2.725 & 2.29 \\
\hline $\mathrm{Sn}_{13} \mathrm{Se}_{81} \mathrm{Sb}_{6}$ & 2.32 & 1.160 & 1.64 & 2.800 & 2.32 \\
\hline $\mathrm{Sn}_{13} \mathrm{Se}_{78} \mathrm{Sb}_{9}$ & 2.35 & 1.175 & 1.70 & 2.875 & 2.35 \\
\hline $\mathrm{Sn}_{13} \mathrm{Se}_{75} \mathrm{Sb}_{12}$ & 2.38 & 1.190 & 1.76 & 2.950 & 2.38 \\
\hline
\end{tabular}

The covalently bonded glassy networks confine mechanically with the interatomic valence forces like bond stretching $\left(\mathrm{N}_{\mathrm{a}}\right)$ and bond bending $\left(\mathrm{N}_{\mathrm{b}}\right)$. These mechanical constraints $\left(\mathrm{N}_{\mathrm{c}}\right)$ are linked with atomic bonding and effective coordination number $\left\langle\mathrm{m}_{\mathrm{eff}}\right\rangle$. The number of constraints per atom arising from bond bending can be calculated by $\mathrm{N}_{\mathrm{b}}=2 \mathrm{~m}$ -3 and from bond stretching by $\mathrm{N}_{\mathrm{a}}=\mathrm{m} / 2$ for the atomic species having coordination number $(\mathrm{m})$. For various compositions of the glassy system $\mathrm{Sn}_{13} \mathrm{Se}_{87-\mathrm{x}} \mathrm{Sb}_{\mathrm{x}}(\mathrm{x}=0,3,6$, 9,12 )by knowing the average number of constraints i.e. $\mathrm{N}_{\mathrm{c}}=$ $\mathrm{N}_{\mathrm{a}}+\mathrm{N}_{\mathrm{b}}$ and the average coordination number (m), the effective coordination number $<\mathrm{m}_{\text {eff }}>$ can be calculated by using the relation:

$$
<m_{\text {eff }}>=\frac{2}{5}\left(N_{c}+3\right)
$$

The computed values of $\mathrm{N}_{\mathrm{a}}, \mathrm{N}_{\mathrm{b}}, \mathrm{N}_{\mathrm{c}}$ and $<\mathrm{m}_{\mathrm{eff}}>$ for the $\mathrm{Sn}_{13} \mathrm{Se}_{87-\mathrm{x}} \mathrm{Sb}_{\mathrm{x}}(\mathrm{x}=0,3,6,9,12)$ glassy system are listed in Table 1. According to Thorpe [18], the system should contain floppy and rigid regions in the range of the glass forming compositions. In $\mathrm{Sn}_{13} \mathrm{Se}_{87-\mathrm{x}} \mathrm{Sb}_{\mathrm{x}}(\mathrm{x}=0,3,6,9,12)$ glassy system compositions the average coordination number varies from 2.26 to 2.38 .

\subsection{Role of Lone Pair Electrons in the Glass Forming Ability}

The prologue of average coordination number projected by Phillips [17] leads to the calculation of the number of lone pairs of chalcogenide glassy systems. The number of lone pair electrons is equal to the difference of all the valence electrons of the system and the shared electrons given by the relation:

$$
\mathrm{L}=\mathrm{V}-<\mathrm{m}>
$$

where $\mathrm{L}$ and $\mathrm{V}$ are lone pair electrons and valence electrons respectively. The number of lone pair of electrons for the $\mathrm{Sn}_{13} \mathrm{Se}_{87-\mathrm{x}} \mathrm{Sb}_{\mathrm{x}}(\mathrm{x}=0,3,9,6,12)$ glassy system is incurred by using equation (3) and is listed in Table 2. It is clear from Table 2 as well as from Figure 1 that with the increase in content of In, the number of lone pair of electrons decreases continuously for $\mathrm{Sn}_{13} \mathrm{Se}_{87-\mathrm{x}} \mathrm{Sb}_{\mathrm{x}}(\mathrm{x}=0,3,6,9,12)$ glassy 
system. It shows that the bond deformation decreases with increase in $\mathrm{Sb}$ content and thus decreasing the flexibility of the system. This is simulated by the interaction between the $\mathrm{Sb}$ ion and the lone pair electrons of a bridging Se atom. The interaction thus decreases the role played by the lone-pair electrons in the glass formation. Zhenhua [19] introduced a simple criterion for computing the power of a chalcogenide system to retain its vitreous state. This criterion includes the study of number of lone pair electrons necessary for obtaining the system in its vitreous state. Thus for a binary system the number of lone-pair electrons must be larger than 2.6 and for ternary system it must be larger than 1 . In our case the values of lone pair electrons lie in the range from 3.48 to 3.24. This explains that the system can be obtained in glassy state.

Table 2. describes the number of lone pair electrons, bond energies of different bonds possible in $\mathrm{Sn}_{13} \mathrm{Se}_{87-\mathrm{x}} \mathrm{Sb}_{\mathrm{x}}(\mathrm{x}=0,3,6,9,12)$ glassy alloys and their cohesive energies.

\begin{tabular}{|c|c|c|c|c|c|}
\hline Composition & $\mathrm{m}$ & $\mathrm{V}$ & $\mathrm{L}=\mathrm{V}-\mathrm{m}$ & Bonds & $\begin{array}{c}\text { Bond } \\
\text { Energy } \\
(\mathrm{eV} / \\
\text { Bond })\end{array}$ \\
\hline $\mathrm{Sn}_{13} \mathrm{Se}_{87}$ & 2.26 & 5.74 & 3.48 & $\mathrm{Sn}-\mathrm{Sn}$ & 1.4834 \\
\hline $\mathrm{Sn}_{13} \mathrm{Se}_{84} \mathrm{Sb}_{3}$ & 2.29 & 5.71 & 3.42 & $\mathrm{Se}-\mathrm{Se}$ & 1.9085 \\
\hline $\mathrm{Sn}_{13} \mathrm{Se}_{81} \mathrm{Sb}_{6}$ & 2.32 & 5.68 & 3.36 & $\mathrm{Sb}-\mathrm{Sb}$ & 1.3099 \\
\hline $\mathrm{Sn}_{13} \mathrm{Se}_{78} \mathrm{Sb}_{9}$ & 2.35 & 5.65 & 3.30 & $\mathrm{Sn}-\mathrm{Se}$ & 2.1340 \\
\hline $\mathrm{Sn}_{13} \mathrm{Se}_{75} \mathrm{Sb}_{12}$ & 2.38 & 5.62 & 3.24 & $\mathrm{Se}-\mathrm{Sb}$ & 1.9065 \\
\hline & & & & $\mathrm{Sn}-\mathrm{Sb}$ & 1.4050 \\
\hline
\end{tabular}

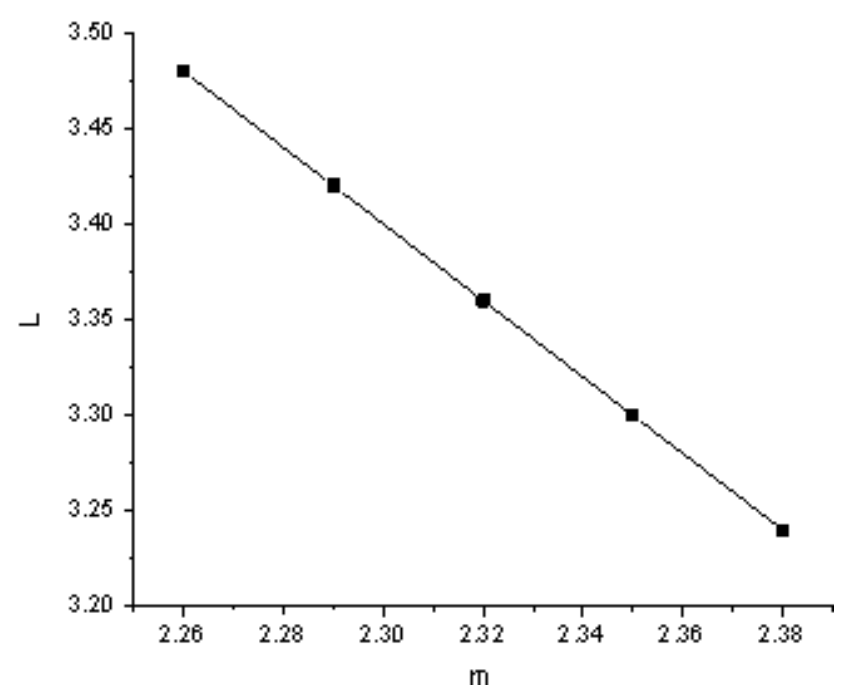

Figure 1. shows the variation of lone pair of electrons (L) with average coordination number $<\mathrm{m}>$ for the $\mathrm{Sn}_{13} \mathrm{Se}_{87 \mathrm{x}} \mathrm{Sb}_{\mathrm{x}}(\mathrm{x}=0,3,6,9,12)$ glassy system.

\subsection{Bond Energies of Homo and Heteronuclear Bonds}

Heteronuclear bonds are formed in preference to homonuclear bonds according to the study by Zachariasen [20]. The different types of bonds possible in the present system are $\mathrm{Sn}-\mathrm{Sn}, \mathrm{Se}-\mathrm{Se}, \mathrm{Sb}-\mathrm{Sb}, \mathrm{Se}-\mathrm{Sn}, \mathrm{Se}-\mathrm{Sb}$ and $\mathrm{Sn}-\mathrm{Sb}$. These bonds are formed in the sequence of their decreasing bond energy. This is equivalent to the assumptionof the maximum possible amount of chemical ordering. This leads to an important conclusion that the bonds between like atoms will only occur if there is an excess of a certain type of atom. The possible bond distribution at various compositions is expressed using chemically ordered network (CONM) model given by Ovshinsky et al [21].

According to CONM model atoms combine more favorably with atoms of different kinds than with those of same kind. Thus the possibility of formation of heteropolar bonds is more as compared to homopolar bonds. Moreover bonds are formed in the sequence of decreasing bond energy until all available valences of the atoms are saturated. The bond energies $\mathrm{E}_{\mathrm{A}-\mathrm{B}}$ for heteronuclear bonds have been calculated by using the relation [22]:

$$
\mathrm{E}_{\mathrm{A}-\mathrm{B}}=\left(\mathrm{E}_{\mathrm{A}-\mathrm{A}} \times \mathrm{E}_{\mathrm{B}-\mathrm{B}}\right)^{0.5}+30\left(\chi_{\mathrm{A}}-\chi_{\mathrm{B}}\right)^{2}
$$

where $\mathrm{E}_{\mathrm{A}-\mathrm{A}}$ and $\mathrm{E}_{\mathrm{B}-\mathrm{B}}$ are the bond energies of the homonuclear bonds and $\chi_{\mathrm{A}}$ and $\chi_{\mathrm{B}}$ are the electro negativities of the atoms involved. The values of the electro negativities of Se, $\mathrm{Sn}$ and $\mathrm{Sb}$ are 2.55 and 1.96 and 2.05 respectively. The calculated values for different bonds are given in Table 2.

\subsection{Average heat of atomization}

The lone-pair forms the top of the valence band and the anti-bonding band forms the bottom conduction band [23] in chalcogenide glasses containing a high concentration of group VI element. Metal atoms can form a dative bond with group VI atoms, lone pair with empty orbital, without any cost of energy, due to the presence of high-energy lone pair on the latter. Dative bonds correspond to empty anti bonding levels which give localized acceptors states in the gap [24]. The optical band gap is closely related to the chemical bond energy.

According to Pauling [25] at standard temperature and pressure of a binary semiconductor formed from atoms A and $\mathrm{B}$ the heat of atomization $\mathrm{H}_{\mathrm{S}}(\mathrm{A}-\mathrm{B})$ is the sum of the heat of formation $\Delta \mathrm{H}$ and the average of the heat of atomization $\mathrm{H}_{\mathrm{S}}{ }^{\mathrm{A}}$ and $\mathrm{H}_{\mathrm{S}}{ }^{\mathrm{B}}$ that corresponds to the average non polar bond energy of the two atoms and is given by the relation:

$$
\mathrm{H}_{\mathrm{S}}(\mathrm{A}-\mathrm{B})=\Delta \mathrm{H}+\frac{1}{2}\left(\mathrm{H}_{\mathrm{S}}^{\mathrm{A}}+\mathrm{H}_{\mathrm{S}}^{\mathrm{B}}\right)
$$

The first term in the above equation is directly proportional to the square of the difference between the electronegativities $\chi_{A}$ and $\chi_{B}$ of the two atoms

$$
\Delta \mathrm{H} \propto\left(\chi_{\mathrm{A}}-\chi_{\mathrm{B}}\right)^{2}
$$

In order to extend this approach to ternary and higher order semiconducting compounds, the average heat of atomization $\overline{\mathrm{H}}_{\mathrm{S}}$ (in kcal per gram-atom) is defined for a compound $\mathrm{A}_{\alpha} \mathrm{B}_{\beta} \mathrm{C}_{\gamma}$ and is considered a direct measure of the cohesive energy and thus of average bond strength given as: 


$$
\overline{\mathrm{H}}_{\mathrm{S}}=\frac{\alpha \mathrm{H}_{\mathrm{S}}^{\mathrm{A}}+\beta \mathrm{H}_{\mathrm{S}}^{\mathrm{B}}+\gamma \mathrm{H}_{\mathrm{S}}^{\mathrm{C}}}{\alpha+\beta+\gamma}
$$

Apparently the $\overline{\mathrm{H}}_{\mathrm{S}}$ values do not contain the heat of formation $(\Delta \mathrm{H})$ as part of cohesive energy even though it is a useful parameter for correlating the physical properties of semiconducting compounds. In case of chalcogenide glasses the heat of formation contributes very little towards the average heat of atomization because the electronegativities of the constituent elements i.e. Se, Sn and $\mathrm{Sb}$ are very similar and in most of the cases of chalcogenide glasses the heat of formation is unknown. In the few materials for which heat of formation is known it accounts only $10 \%$ for the heat of atomization and is therefore neglected. Hence for binary chalcogenide glasses $\mathrm{H}_{\mathrm{S}}(\mathrm{A}-\mathrm{B})$ is given by:

$$
\mathrm{H}_{\mathrm{S}}(\mathrm{A}-\mathrm{B})=\frac{1}{2}\left(\mathrm{H}_{\mathrm{S}}^{\mathrm{A}}+\mathrm{H}_{\mathrm{S}}^{\mathrm{B}}\right)
$$

whereas for ternary and higher order compounds, $\overline{\mathrm{H}}_{\mathrm{S}}$ is given by equation (7). The values of heat of atomization for $\mathrm{Se}, \mathrm{Sn}$ and $\mathrm{Sb}$ elements are $226.0 \mathrm{~kJ} / \mathrm{mol}, 302.0 \mathrm{~kJ} / \mathrm{mol}$ and $262.04 \mathrm{~kJ} / \mathrm{mol}$, respectively. The calculated average heat of atomization $\overline{\mathrm{H}}_{\mathrm{S}}$ and average single bond energy $\left(\overline{\mathrm{H}}_{\mathrm{S}} / \mathrm{m}\right)$ are given in Table 3 , where $\mathrm{m}$ is the average coordination number. It is evident from the Table 3 that the heat of atomization increases with the increase of $\mathrm{Sb}$ content while the average single bond energy $\left(\overline{\mathrm{H}}_{\mathrm{S}} / \mathrm{m}\right)$ which is a measure of cohesive energy decreases with the increase of Sb content. This decrease in the average single bond energy with the increase of $\mathrm{Sb}$ content may be responsible for the decrease of optical band gap.

Table 3. describes the values of average heat of atomization, average single bond energy, mean bond energy and glass transition temperature for $\mathrm{Sn}_{13} \mathrm{Se}_{87-\mathrm{x}} \mathrm{Sb}_{\mathrm{x}}(\mathrm{x}=0,3,6,9,12)$ glassy alloys.

\begin{tabular}{|c|c|c|c|c|}
\hline Composition & $\begin{array}{c}\bar{H}_{S} \\
\text { (eV/bond) }\end{array}$ & $\begin{array}{c}\bar{H}_{S} / m \\
\text { (eV/bond) }\end{array}$ & $\begin{array}{c}<\mathrm{E}> \\
\text { (eV/bond) }\end{array}$ & $\mathrm{T}_{\mathrm{g}}(\mathrm{K})$ \\
\hline $\mathrm{Sn}_{13} \mathrm{Se}_{87}$ & 2.447 & 1.083 & 2.13 & 385.61 \\
\hline $\mathrm{Sn}_{13} \mathrm{Se}_{84} \mathrm{Sb}_{3}$ & 2.459 & 1.074 & 2.17 & 395.90 \\
\hline $\mathrm{Sn}_{13} \mathrm{Se}_{81} \mathrm{Sb}_{6}$ & 2.470 & 1.065 & 2.21 & 407.31 \\
\hline $\mathrm{Sn}_{13} \mathrm{Se}_{78} \mathrm{Sb}_{9}$ & 2.481 & 1.056 & 2.25 & 419.78 \\
\hline $\mathrm{Sn}_{13} \mathrm{Se}_{75} \mathrm{Sb}_{12}$ & 2.492 & 1.047 & 2.29 & 433.28 \\
\hline
\end{tabular}

\subsection{Mean Bond Energy and Glass Transition Temperature}

The properties of chalcogenide glasses are in close relation with overall mean bond energy $<\mathrm{E}>$. The mean bond energy of the system is calculated by using the relation:

$$
<\mathrm{E}>=\mathrm{E}_{\mathrm{C}}+\mathrm{E}_{\mathrm{rm}}
$$

where $E_{c}$ is the overall contribution towards bond energy arising from strong heteronuclear bonds and $\mathrm{E}_{\mathrm{rm}}$ is the contribution arising from weaker bonds that remain after the number of strong bonds will become maximum i.e. average bond energy per atom of the 'remaining matrix'. For
$\mathrm{Sn}_{\mathrm{x}} \mathrm{Se}_{\mathrm{y}} \mathrm{Sb}_{\mathrm{z}}$ system (where $\mathrm{x}+\mathrm{y}+\mathrm{z}=1$ ), and in the selenium rich region,

$$
E_{c}=4 x E_{S n-S e}+3 z E_{S e-S b}
$$

and

$$
E_{r m}=\frac{[2 y-4 x-3 z]}{<m>} E_{S e-S e}
$$

The calculated values of the mean bond energy are given in Table 3. This is clear from mean bond energy data that when $\mathrm{Sb}$ content increases, the mean bond energy of the system increases.

The glass transition temperature $T_{g}$ for the chalcogenide glasses is theoretically predicted as a first approximation by covalent bond approach of Tichy and Ticha [26, 27]. Tichy and Ticha examined 186 chalcogenide glasses with $\mathrm{T}_{g}$ ranging from $320 \mathrm{~K}$ to $760 \mathrm{~K}$, and obtained a good correlation between $\mathrm{T}_{\mathrm{g}}$ and $<\mathrm{E}>$ in the form

$$
T_{g}=311[\langle E\rangle-0.9]
$$

which satisfies the Arrhenius relation for viscosity.

Figure 2 shows the variation of glass transition temperature with mean bond energy. The glass transition temperature increases with the increase in mean bond energy. The glass transition temperature for the various compositions of the $\mathrm{Sn}_{13} \mathrm{Se}_{87-\mathrm{x}} \mathrm{Sb}_{\mathrm{x}}(\mathrm{x}=0,3,6,9,12)$ glassy system has been calculated using equation (12) and is listed in Table 3. The glass transition temperature of the system under consideration shows an increase with the increase of the $\mathrm{Sb}$ content. This increase in the value of the glass transition temperature with increasing $\mathrm{Sb}$ content in glass forming alloys may be due to the accumulation of three dimensional structural units $\mathrm{SbSe}_{3 / 2}$ and $\mathrm{SnSe}_{4 / 2}$ in them and due to the decrease of the content of chain like formation of excess Se.

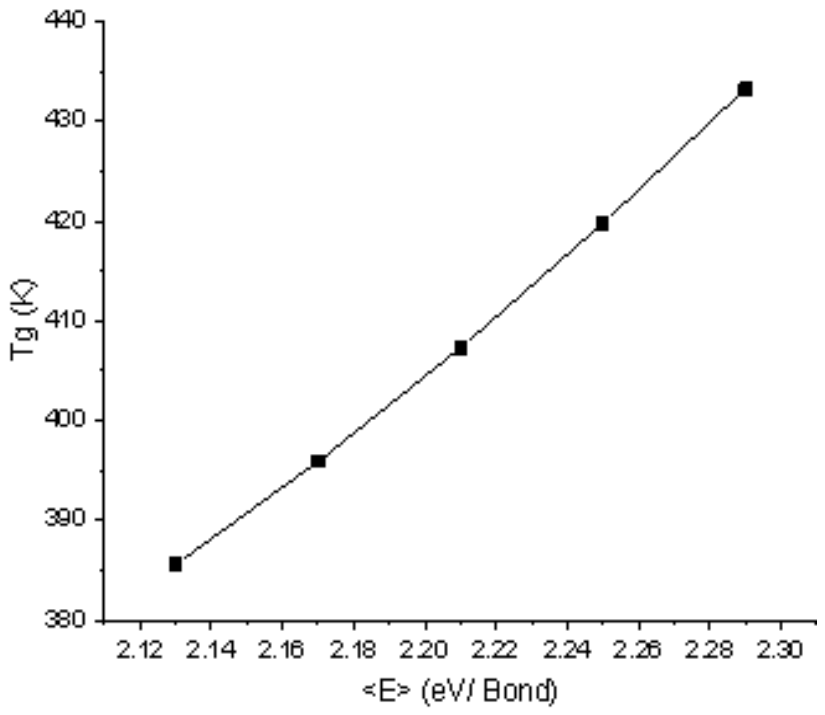

Figure 2. shows the variation of glass transition temperature $\left(\mathrm{T}_{\mathrm{g}}\right)$ with mean bond energy $<\mathrm{E}>$ in the $\mathrm{Sn}_{13} \mathrm{Se}_{87-\mathrm{x}} \mathrm{Sb}_{\mathrm{x}}(\mathrm{x}=0,3,6,9,12)$ glassy system.

\subsection{Theoretical Band Gap, Cohesive Energy and Deviation of Stoichiometry}


For binary system theoretically band gap $\left(E_{g}\right)$ can be calculated by the relation given by Shimakawa [28]:

$$
E_{g(A B)}=V E_{g(A)}+(1-V) E_{g(B)}
$$

where $V$ is the volume fraction of element $\mathrm{A}$ and $(1-V)$ is the volume fraction of element $\mathrm{B}$. $\mathrm{E}_{\mathrm{g}(\mathrm{A})}$ and $\mathrm{E}_{\mathrm{g}(\mathrm{B})}$ are energy gaps of elements A and B respectively. The same relation can be applied for ternary systems. It is inferred that with the addition of $\mathrm{Sb}$ in $\mathrm{Sn}-\mathrm{Se}$ alloy the band gap considerably increases. This can be associated with increase in average heat of atomization [29] as well as decrease in electronegativity [30]. There is direct relationship between the $H_{s}$ and $E_{g}$ given by Aigrain and Balkanski [31] which leads to the important conclusion that the band gap increases with the increase in Sn content. Cohesive energy is the stabilization energy of an infinitely large cluster of material per atom. It gives a measure of the average bond strength. Chemical Bond Approach method [20] has been used to find the cohesive energy of the system under study. According to this method, bonds are formed in the order of their decreasing bond energies. So the cohesive energy is calculated by summing the bond energies over all bonds expected in the present system. The values of the bond energy for the different compositions of the $\mathrm{Sn}_{13} \mathrm{Se}_{87-\mathrm{x}} \mathrm{Sb}_{\mathrm{x}}$ (x $=0,3,6,9,12)$ system are shown in Table 2 . The values of cohesive energy show an increasing trend with the increase of $\mathrm{Sb}$ content. This increase in the value of cohesive energy can be assigned to the formation of more and more heteronuclear bonds of $\mathrm{Sn}$ with $\mathrm{Se}$ with the increase in $\mathrm{Sb}$ content. These Sn-Se bonds have the highest value of bond energy for the present glassy alloy.

Cohesive energy of samples has been calculated by chemical bond approach [20].

$$
\text { C. E. }=\sum\left(\frac{\mathrm{C}_{\mathrm{t}} \mathrm{D}_{\mathrm{t}}}{100}\right)
$$

where $C_{t}$ represent the number of expected chemical bonds and $D_{t}$ is the energy of each bond respectively. The calculated values of cohesive energies of different glassy samples along with excess Se-Se bonds are given in the Table 4. It increases with the addition of Sb content, which means average stabilization energy also increases. Increase in $\mathrm{CE}$ thus causes a gap between bonding and anti-bonding orbital.

Deviation of stoichiometry (R) is defined as the ratio of covalent bonding possibilities of chalcogen atoms. It is calculated by the relation:

$$
R=\frac{Y N_{S e}}{X N_{S n}+Z N_{S b}}
$$

where $\mathrm{X}, \mathrm{Y}, \mathrm{Z}$ are the atomic fractions of $\mathrm{Sn}, \mathrm{Se}$ and $\mathrm{Sb}$ respectively. This approach leads to an important conclusion that for $\mathrm{R}>1$, system is chalcogen rich and for $\mathrm{R}<1$, system is chalcogen poor and for $\mathrm{R}=1$, is threshold value where heteropolar bonds exists. From Table 4 it is clear that $\mathrm{R}>1$ for all the samples under consideration and hence system under investigation is chalcogen-rich region.
Table 4. describes the values of cohesive energies, excess Se-Se bonds, parameter $\mathrm{R}$ and band gap for $\mathrm{Sn}_{13} \mathrm{Se}_{87-\mathrm{x}} \mathrm{Sb}_{\mathrm{x}}(\mathrm{x}=0,3,6,9,12)$ glassy alloys.

\begin{tabular}{|c|c|c|c|c|}
\hline Composition & $\begin{array}{c}\text { Excess } \\
\text { Se-Se } \\
\text { bonds }\end{array}$ & $\begin{array}{c}\mathrm{CE}(\mathrm{k} \\
\mathrm{cal} / \mathrm{mole})\end{array}$ & $\mathrm{R}$ & $\mathrm{E}(\mathrm{eV})$ \\
\hline $\mathrm{Sn}_{13} \mathrm{Se}_{87}$ & 122 & 45.54 & 3.34 & 1.69 \\
\hline $\mathrm{Sn}_{13} \mathrm{Se}_{84} \mathrm{Sb}_{3}$ & 91 & 46.09 & 2.75 & 1.64 \\
\hline $\mathrm{Sn}_{13} \mathrm{Se}_{81} \mathrm{Sb}_{6}$ & 76 & 46.17 & 2.31 & 1.58 \\
\hline $\mathrm{Sn}_{13} \mathrm{Se}_{78} \mathrm{Sb}_{9}$ & 61 & 46.25 & 1.97 & 1.52 \\
\hline $\mathrm{Sn}_{13} \mathrm{Se}_{75} \mathrm{Sb}_{12}$ & 46 & 46.33 & 1.70 & 1.46 \\
\hline
\end{tabular}

\section{Conclusions}

It is evident from the theoretical investigation that the change in composition of $\mathrm{Sn}_{13} \mathrm{Se}_{87-\mathrm{x}} \mathrm{Sb}_{\mathrm{x}}(\mathrm{x}=0,3,6,9,12)$ glassy system changes almost all the physical parameters. The present work on $\mathrm{Sn}_{13} \mathrm{Se}_{87-\mathrm{x}} \mathrm{Sb}_{\mathrm{x}}(\mathrm{x}=0,3,6,9,12)$ glassy system shows that the average coordination number, number of constraints, average heat of atomization, mean bond energy, cohesive energy and glass transition temperature increases with the increase of Sb content while the number of lone pair of electrons, band gap and average single bond energy $\left(\overline{\mathrm{H}}_{\mathrm{S}} / \mathrm{m}\right)$ decreases. The increase in glass transition temperature $\left(\mathrm{T}_{\mathrm{g}}\right)$ and cohesive energy with increasing $\mathrm{Sb}$ content is explained on the basis of chemically ordered network model by which heteronuclear bonds are preferred to homonuclear ones.

\section{REFERENCES}

[1] Fritzsche, J. Phys. \& Chem. Solids 68, 878 (2007).

[2] P. Pattanayak, S. Asokan, Europhys. Lett. 75, 778 (2006).

[3] H. F. Hamann, M. O. Boyle, Y. C. Martin, M. Rooks, H. K. Wickramasinghe, Nature Mater. 5, 383 (2006).

[4] Balitska, O. Shpotyuk, H. Altenberg, J. Non-Cryst. Solids 352 4809 (2006).

[5] A. Ganjoo, H. Jain C. Yu, R. Song, J. V. Ryan, J. Irudayaraj, Y. J. Ding, C.G. Pantano, J. Non-Cryst. Solids 352, 584 (2006).

[6] M. Bayindir, O. Shapira, D. S. Hinczewski, J. Viens, A. F. Abouraddy, J. D. Joannopoulos, Y. Fink, Nature Mater. 4, 820 (2005).

[7] S. A. Mcdonald, G. Konstantatos, S. Zhang, P. W. Cyr, E. J. D. Klem, L. levinal, W. H. Sargent, Nature Mater. 4, 138 (2005).

[8] G. Boudebs, S. Cherukulappaurath, M. Guignrd, J. Troles, F. Smektala, F. Sanchez, Optics Commun. 230, 331 (2004).

[9] M. Popescu, in "Non-Crystalline Chalcogenides" Kluwer Academic, Boston (2001).

[10] P. Sharma, V. S. Rangra, S. C. Katyal, P. Sharma, Optoelectronics Adv. Mater.-R.C. 1, 363 (2007). 
[11] K. Tanaka, K. Shimakawa, Phys. Status Solidi. B 246, 1744 (2009)

[12] P. S. R. Alerigi, H. Dalaver, Anjum, Y. Zhang, X. Yang, A. Benslimane, K. Tien, M. N. Hedhili, A. Mohammad, S. O. Boon, J. Appl. Phys. 113, 044116 (2013).

[13] N. Mehta, M. Zulfequar, A. Kumar, J. Optoelectron. Adv. Mater 6, 441 (2004)

[14] D. V. Harea, I. A. Vasilev, E. P. Colomeico, M. S. Lovu, J. Optoelectron. Adv. Mater. 5, 1115 (2003).

[15] P. Kumar, R. Thangaraj, J. Non-Cryst. Solids 352, 2288 (2006).

[16] P. Sharma, S.C. Katyal, Thin Solid Films 517 (2009) 3813.

[17] J. C. Phillips, J. Non-Cryst. Solids 34, 153 (1979).

[18] M. F. Thorpe, J. Non-Cryst. Solids 57, 355 (1983).

[19] L. Zhenhua, J. Non-Cryst. Solids 127, 298 (1991).

[20] W. H. Zachariasen, J. Am. Chem. Soc. 54, 3841 (1932).

[21] J. Bicerno, S. R. Ovshinsky, J. Non-Cryst. Solids 74, 75 (1985).
[22] P. Sharma, S. C. Katyal, J. Non-Cryst. Solids 354 (2008) 3836 .

[23] M. Kastner, Phys. Rev. Lett. 28, 355 (1972).

[24] S. R. Ovshinsky, Selected papers, "Disordered Materials: Science and Technology", D. Adler (Ed.) Amorphous Institute Press, USA 83 (1982).

[25] L. Pauling, "The Nature of Chemical Bond", Cornell University Press, New York (1963).

[26] L. Tichy, H. Ticha, J. Non-Cryst. Solids 189, 141 (1995).

[27] L. Tichy, H. Ticha, Mater. Lett. 21, 313 (1994).

[28] K. Shimakawa, J. Non-Cryst.Solid. 43229 (1981).

[29] A.H. Ammar, A.M. Farid, S.S. Fouad Physica B 307, 64 (2001).

[30] V. Pandey, S. K. Tripathi, A. Kumar, J. Optoelectron. Adv. Mater. 8 (2), 796 (2006).

[31] C. Benoit, P. Aigrain and M. Balkanski, "Selected Constants Relative to Semiconductors". (Pargamon Press, New York, 1961). 